\title{
Back to the Future: Library Book Clubs for Individuals with Intellectual Disability (ID)
}

\author{
Matthew Conner, University of California, Davis, USA \\ Leah Plocharczyk, Florida Atlantic University, USA
}

\begin{abstract}
This article provides context for library services for individuals with intellectual disability (ID) and then provides a case study and preliminary data on new efforts in the field for public libraries, school media centers, and academic libraries connected with the educational system. While many libraries are dedicated to serving diverse populations, they have done little to support individuals with ID who have difficulty using library services and accessing their collections. Efforts to advertise, to develop specialized collections, and to utilize assistive technology have floundered on high costs and low returns. These shortcomings are especially critical for adults with ID. While the law mandates the inclusion of individuals with ID in the public school system, there are few opportunities for education, employment, or socializing for those who age out; the library, as a fundamental public institution, is one of the few resources available to them. For the benefit of both libraries and adults with ID, it is critical that libraries develop improved services for this group of patrons. The case study in this article provides data on a book club for persons with ID held at an academic library and based on the model of the Next Chapter Book Club (NCBC) organization. By comparing data between the case study and 30 similar book clubs at public libraries throughout the nation, the article develops a profile of what these book clubs do and how to measure their successes. We conclude that such clubs represent a low-cost, effective way for libraries to support persons with ID that helps libraries fulfill their mission of serving diverse groups and provides critical support to this particular population.
\end{abstract}

Keywords: book club; intellectual disability; library

Publication Type: case study

\section{Introduction}

$\mathrm{H}$ istorically libraries have been recognized as welcoming institutions that provide free access to information and services to the public. Librarians and library staff pride themselves on providing sufficient resources and outreach to marginalized populations, including those who are homeless, those who are impoverished, and those with disabilities. However, one particular population, adults who are cognitively or physically varied, defined as having intellectual and developmental disabilities (IDD), remains neglected. Intellectual Disability (ID) is a subset of this syndrome that refers to "significant limitations in both intellectual functioning and in adaptive behavior, which covers every day social and practical skills" and "originates before the age of 18" (American Association of Intellectual and Developmental Disabilities, 2019). Adaptive behaviors refer to the conceptual, social, and practical skills that one needs to perform everyday life activities including one's ability to

The International Journal of Information, Diversity, \& Inclusion, 3(4), 2019

ISSN 2574-3430, jps.library.utoronto.ca/index.php/ijidi/index

DOI: $10.33137 /$ ijidi.v3i4.33009 
manage money and time, to interact socially, to problem solve, and to handle personal care (American Association of Intellectual and Developmental Disabilities, 2019). A developmental disability (DD) is a condition caused by "an impairment in physical, learning, language, or behavior areas. These conditions begin during the developmental period and usually last throughout a person's lifetime" (Center for Disease Control and Prevention, 2018). Developmental disabilities can include conditions such as ADHD, autism spectrum disorder, cerebral palsy, hearing loss, learning disabilities, and vision impairment (Center for Disease Control and Prevention, 2018). Individuals with ID can have DD as well and IDD is an umbrella term that refers to individuals who may have both of these conditions in any combination.

The term "disability" in IDD implies the inclusion of both "physical disability" and "learning disability," both terms which have general and specific technical usages. A physical disability is defined as an "atypicality of body parts and function" such as amputation of limbs and respiratory disease (Clute, 2013). A learning disability is a condition which affects the processing of information without impinging on the individual's intelligence and includes such conditions as dyslexia, dyscalculia, and dysgraphia (Learning Disabilities Association of America, 2019; National Institute for Neurological Disorders and Stroke, 2019). Many conditions cross over between these two categories, however, and throw their distinctions into doubt. Blindness is clearly a physical disability, for example, yet who can dispute that it impedes the processing of information? Similarly, Non-Verbal Learning Disabilities, which can include weak motor skills, are technically learning disabilities, but they qualify as physical disabilities as well. IDD, combining physical and cognitive limitations, can be imagined as a Venn Diagram intersection of all disabilities in these categories. That is, conditions of IDD can and frequently do consist of both physical and learning disabilities at the same time. While this degree of constraint makes patrons with IDD particularly difficult to serve, by the same token, addressing these difficulties has implications for people with all forms of disabilities that libraries serve. This paper will refer to its population of students as those with ID, partly as a shorthand for IDD, and partly because it most accurately represents the students under study, who were far more likely to have cognitive disabilities than developmental disabilities.

The American Library Association (ALA) has addressed disability in its own Bill of Rights, promulgated in 1939 to celebrate the $150^{\text {th }}$ anniversary of the Bill of Rights of the United States.

Access to materials should not be restricted by any presuppositions about information needs, interests, or capacity for understanding. Library staff should actively research and integrate existing and emerging accessible technologies and provide services to assist patrons when conflicts exist. The availability of these technologies and services should be marketed and available to all patrons. When libraries present information in formats that are accessible to all users, and do not limit access to physical facilities or virtual library structures, they eliminate barriers to information. (American Library Association, 2018)

The commitment is explicit. Yet, the defining condition of persons with ID often restricts them from using the library's reading materials which is our core service. Libraries are caught between their values and practical realities. Meanwhile, persons with ID remain without appropriate access to one of the major social institutions, one of the very few, that remains open to them after they have aged out of the public school system. This paper will review the state of this problem and provide a preliminary investigation into possible solutions. We will discuss public libraries and academic libraries which serve as adjuncts to the educational system. While we

The International Journal of Information, Diversity, \& Inclusion, 3(4), 2019

ISSN 2574-3430, jps. library.utoronto.ca/index.php/ijidi/index

DOI: $10.33137 /$ ijidi.v3i4.33009 
have no information on school media centers, we assume, with their placement in the educational system, that findings about public libraries will apply to them as well. We do not consider corporate and specialized libraries which lie outside the educational system.

\section{Previous Efforts Unsuccessful}

Librarians have made attempts to accommodate patrons with ID, and these efforts fall broadly into three categories: outreach, specialized centers, and mainstreaming (Wells, 1995, p. 211). The first of these efforts, outreach, is made through extensive advertising and publicity in which individuals with ID are invited into the library in hopes that they will establish a connection on their own. A second category of effort is the creation of specialized centers which collect reading material for patrons with ID. Yet it is unknown what reading materials best meet their needs. Some theories suggest material that is entertaining and comprehensible, or that which contains more advanced content on advocacy and self-help for the patron and his or her supporters. These centers also include assistive technology. Early technological attempts introduced devices to cope with obvious physical and learning disabilities such as blindness and deafness. Braille and tape recorders were enlisted for these purposes. Since that time a wider array of technologies has been enlisted to provide more effective service and to support a wider range of disabilities. These include mechanical devices that attach to books to make the pages easier to turn, chairs and desks that raise and lower, computerized technology for enlarging fonts and voice synthesizers for converting text to sound. Categorically, these are meant to address learning disabilities that interfere with the transmission of information, but not to deal with cognitive deficiency. As it turns out, some of these tools, especially newer computerized devices, can help those with cognitive disabilities, partly because developmental disabilities mix with intellectual ones in the condition of IDD, and partly because new methods have been found to apply the technology. However, this movement is still in its infancy. The final category of effort is called "mainstreaming," wherein the entire library, including its facility, collections, services, equipment and staffing, are converted to be uniformly accessible to patrons with ID. Mainstreaming is the most expensive option. Generally, these three categories provide low return for cost. None looks to meet the challenge we describe on a significant scale (Mulliken \& Atkins, 2009).

\section{New Possibilities}

In 2002, Dr. Tom Fish, Director of Social Work at the Nisonger Center for Excellence in Disabilities at The Ohio State University, saw a need to create more meaningful experiences for adults with ID who were looking for opportunities for socialization and mental stimulation (Fish \& Rabidoux, 2009). This grassroots organization known as the Next Chapter Book Club (NCBC) was developed as a creative solution to fill this void and to provide continuing education for adults with ID after they transition out of the public school system. Fish's vision was to launch local clubs throughout central Ohio where individuals with ID could engage socially in public with one another over a good book. This idea creatively circumvented the barrier of literacy by merging reading and socialization as shared goals, both of which meet the needs of persons with ID. What began as a handful of clubs in Ohio expanded on its own initiative in social media into thriving chapters throughout the United States. Presently, NCBC has an international scope as well, with chapters located in Europe, Great Britain, and Australia.

In determining the all-important setting for these clubs, NCBC sought to balance the competing demands of a public, sociable environment with a safe place where adults with ID would not feel

The International Journal of Information, Diversity, \& Inclusion, 3(4), 2019

ISSN 2574-3430, jps.library.utoronto.ca/index.php/ijidi/index

DOI: $10.33137 /$ ijidi.v3i4.33009 
conspicuous or cause disruption. Initially, the clubs found the settings they were seeking in cafes and bookstores. Libraries were perceived as silent spaces and avoided due to old stereotypes. This has changed over time, however, as libraries have adopted more open attitudes and NCBC has gained new understanding of libraries as inclusive spaces. Within the last seven years, over 60 public libraries have registered as chapters with NCBC.

Another notable program that provides reading and socialization opportunities for adults with ID is the Books for Dessert program, developed independently by the New York Public Libraries (Port Washington Public Library, n.d.). This club was created by a concerned mother, whose son with Down syndrome had aged out of the public school system and was struggling to find mental stimulation while sitting at home. With other like-minded advocates, she formed a book club for adults with ID which allowed the members to read and discuss books in a library setting (Marcotte, 2019). The club is run out of the Port Washington Public Library in Long Island by special education teachers and a group of volunteers who facilitate conversations among the members and lead the discussion groups (Port Washington Public Library, n.d.). Similar to the NCBC, Books for Dessert's main objective is to promote socialization and intellectual stimulation for adults with ID who may not otherwise have the opportunity to establish a social network on their own. However, Books for Dessert takes a more systematic approach by using staff trained in special education. The NCBC groups are led solely by volunteers who have undergone the organization's own training.

\section{Study Design and Data}

In 2017, a university satellite campus in Southeast Florida was the first academic library to become an affiliate of the NCBC. This branch campus hosts a grant-funded post-secondary program for adults with ID who enroll in modified college courses. While attending the program's orientation, the assistant director (one of the authors of this paper) learned about NCBC from a mother whose son was a member of a book club and had enjoyed it. She researched the program and later completed the online affiliate training with two of her library staff members to form an official NCBC chapter/club which has operated for almost three years. As part of an assessment program, the assistant director compiled data on her book club and sought to compare it with other NCBC clubs at libraries. Through NCBC, she identified 60 public libraries operating book clubs of whom she contacted 30 to survey. By comparing these survey results with her own data, she hoped to provide a preliminary study of what librarians are doing to adapt the NCBC mission to libraries and to what extent they are successful.

The affiliates' club coordinators were contacted via email and asked if they would be willing to participate in a brief phone conversation to answer questions about their clubs' operations. Thirty out of 60 libraries participated in the study. The same nine questions were asked of each coordinator.

1. How long have you been in operation?

2. Where do you get your members and how do you recruit them?

3. Where do you meet?

4. What organizations if any do you cooperate with?

The International Journal of Information, Diversity, \& Inclusion, 3(4), 2019

ISSN 2574-3430, jps.library.utoronto.ca/index.php/ijidi/index

DOI: $10.33137 /$ ijidi.v3i4.33009 
5. How do you select the readings?

6. Are there additional activities besides the readings that you have used, such as games?

7. Do you go on outings?

8. How successful has the club been, and how do you measure success?

Each interview lasted at least 30 minutes and some were longer than an hour. Where necessary, some surveys were sent electronically and completed via email.

\section{Survey Results}

The following section provides an overview of the survey results. The academic librarian found it useful to compare the experience of public library clubs with her own. Because all the clubs served the same population-adults with ID-and because all operated under the guidelines of the NCBC, their experiences were significantly comparable, despite the fact that academic libraries and public libraries may have very different missions. Functionally, the library book clubs were the same. Nevertheless, to acknowledge the traditional distinction between public and academic libraries, we will report data for the public libraries generated by a survey, then compare it to the experience of the academic library, based on other kinds of data, in the next section.

\section{Length of Operation}

As indicated earlier, the phenomenon of library book clubs for patrons with ID is new. Eighteen of the clubs have been in operation for only one to two years. Six clubs began operating between two and five years ago, and only three clubs have operated for more than eight years.

\section{Recruitment Sources}

Recruitment and outreach are important issues for libraries. For the specialized population here, the vast majority of clubs rely on partnerships with community mental health and disabilities organizations. Twenty-two clubs recruit book club members through these venues. Eight clubs conduct outreach and advertising for additional recruitment, and seven clubs partner with special education programs in local high schools. Another six clubs cited social media as a recruitment tool and four clubs use "other" methods.

\section{Meeting Location}

Twenty-five clubs meet in the library itself while seven meet outside in a public setting.

\section{Organizational Partnerships}

Survey question four asked about organizational partnerships. Twenty-one clubs said that they partnered with local disabilities organizations and relied upon them for transportation to and from club sessions, and for organizing some of the clubs' activities. Only two clubs reached out to local high schools and recruited their members through the schools' special education programs. A total of five clubs cited "other" as partnerships.

The International Journal of Information, Diversity, \& Inclusion, 3(4), 2019

ISSN 2574-3430, jps. library.utoronto.ca/index.php/ijidi/index

DOI: $10.33137 /$ ijidi.v3i4.33009 


\section{Reading Selection}

The question of reading selection is fundamental to the enterprise of book clubs as well as librarians. And it was of particular interest to the book club coordinator who had struggled with choosing materials that would appeal to her club's diverse interests and varied reading abilities. The special educators running the post-secondary program suggested Hi-Lo books, which offer age-appropriate content at a simple level that would affirm an adult identity for the students. Fourteen of the respondents said that they relied upon reading lists compiled by NCBC. Thirteen of club coordinators relied upon children's literature, and 11 club facilitators chose books with animal themes. Choice played a role in selection. Ten clubs asked club members to vote from a list of selections. Nine clubs relied entirely on suggestions from the group. Young Adult novels were slightly less popular than children's literature and only seven clubs reported reading them, followed by action, adventure, and mystery, which tied with the adapted classics with only five clubs reading these genres. Surprisingly Hi-Lo books bottomed out with only four clubs using them, followed by four clubs who designated the "other" category.

\section{Games, Other Activities}

Question six addressed the second half of NCBC's mission. In addition to reading, the clubs promote socializing, and this question explored what form this socialization took. Eighteen of the respondents indicated that they engaged in social activities such as conversation and catching up with the members' experiences since the previous meeting. Ten clubs reported parties, including birthday celebrations, holiday gatherings, and end-of-the-year fêtes. Nine of the clubs used educational activities as a supplement to reading, while eight of the clubs noted that they play games in addition to reading. Four of the NCBC club facilitators noted that members worked on crafts in their club sessions.

When interviewed, most of the club facilitators responded that playing games was not a part of their weekly activities. Many were surprised at the suggestion of including them. The majority of the clubs focused on reading with a brief amount of time set aside for members to socialize and catch up with each other.

\section{Weekly Attendance}

The NCBC guidelines for group size are fairly strict, calling for between four and eight participants. Eleven of the clubs cited a weekly attendance of between four and six members. Nine of the clubs reported between seven and eight members each week, and eight clubs had eight or more members per session. Only one club reported an average attendance between one and three members. These numbers have a weighted average of six attendees per session. The fact that the clubs are pressing up against the upper limit of club size suggests to us the vitality of the concept.

\section{Outings}

As an extension of socialization, question eight asked whether the club went outside of its regular setting for field trips. Twelve clubs report trips to local cafes, restaurants and occasionally movies, whereas 18 clubs confined their meetings to their regular setting. The majority of club facilitators cited issues with transportation and concerns with liability as reasons for not taking their club members on field trips.

The International Journal of Information, Diversity, \& Inclusion, 3(4), 2019

ISSN 2574-3430, jps.library.utoronto.ca/index.php/ijidi/index

DOI: $10.33137 /$ ijidi.v3i4.33009 


\section{Measures of Success}

The final question touched on the fundamental issue of assessment. How does a facilitator know if something is working? The already difficult issue of assessment is compounded by the potential difficulties persons with ID may experience with communication and understanding. For these reasons, specialized techniques of testing and assessment for special education have evolved that are outside of the scope of this paper. Yet, based on the foundational concept of mainstreaming, which holds that persons with ID should interact with non-specialists, we ask how librarians might assess the teaching environment of NCBC, a more limited issue of classroom management familiar to educators in all subjects. Twenty-two club facilitators cited attendance and retention (continuation in subsequent editions of the club) as the overwhelming measures of success. Indeed, attendance is fundamental to everything else and is one of the few types of data available that can be easily quantified.

Otherwise, the facilitators did not conduct a formal assessment but rather observed members' behavioral clues to determine whether they seemed to be engaged and having fun. Sixteen facilitators reported monitoring the members for expressions of excitement and joy. Eleven facilitators relied upon the members' comments regarding their experiences in book club. Eight facilitators cited observed improvements in the club members' reading abilities and socialization skills.

\section{Discussion}

As suspected, the case of the academic library club was very similar to that of the public libraries in the survey. We will discuss points of similarity and difference between the two categories in the course of interpreting the survey results above. The NCBC public library book clubs are a recent phenomenon appearing within the last seven years, and the academic library club falls into this range, having begun three years ago. This timing resulted from the development of NCBC in the first decade of the century and a time lag before it was extended to public libraries. The academic library club for those with ID is the first we know of, likely because the more specific mission of academic libraries for their own select clientele has made them a less obvious venue for those with ID.

Recruitment for the public library clubs comes from institutions in the area serving adults with ID. The academic library also relied on an institution in the form of its campus Post Secondary Education (PSE) program dedicated to students with ID. The majority of public library clubs met in the library with the remaining quarter outside, and this accords with the academic club which has met both inside and outside of the library.

Attendance rates for public library clubs and the academic club are similar in that most clubs have close to the maximum of eight allowed by NCBC guidelines and both the public and academic libraries have continuity of members between clubs. Data was only available for the academic club which had $40 \%$ of attendees attending half or more of the clubs available after their first term.

The reading selection experience was the same for both public and academic library clubs. There are no magic bullet answers. If anything, the students tend to prefer children's literature to adult content in contrast to the theory of Hi-Lo, but the most success was found with allowing students to choose their readings.

The International Journal of Information, Diversity, \& Inclusion, 3(4), 2019

ISSN 2574-3430, jps.library.utoronto.ca/index.php/ijidi/index

DOI: $10.33137 /$ ijidi.v3i4.33009 
The non-reading activities were the source of the only significant difference between the public and academic library clubs. The public libraries preferred conventional socialization in the form of discussions and parties with little use of educational games. While the academic library club also encouraged socialization, it made much heavier use of games, which were quite successful. One might suppose that the educational format of games was due to the academic library's more rigorous educational standards, but since the student participants had similar capacities across all libraries, this is likely not true. We speculate that games integrated with readings represent an advance of NCBC's combined mission to promote reading and socializing. Games also support theories of pre-literate learning in which a language-rich environment facilitates the beginning stages of the reading process (Barratt-Pugh \& Rohl, 2015, p. 4). Properly chosen and administered, we suggest that games have a potential to enhance the experience of all NCBC book clubs.

While a minority of clubs tried field trips and outings, the majority stayed in their original location and cited issues of transportation and liability as reasons not to venture outside. For similar reasons, the academic club did not travel outside of its regular meeting space.

As measures of success, the public library clubs cited the simple fact of attendance. If students showed up voluntarily, it implied that they must enjoy the club; even moreso if they continued their attendance over a long period. Otherwise, the criteria was simply whether the students appeared to be interested and engaged, the practical criteria of any teacher. By both measures, all the responding institutions reported success. The academic club employed a variety of means to investigate success which came to the same conclusion. To evaluate each session, the librarian and her facilitators used a list of approximately 10 behavioral codes to identify typical behaviors of students. These were divided into three categories: participation, socialization, and isolation. Participation consisted of behaviors that supported the lesson, such as supporting other students and actively playing the games. Socialization consisted of interactions with other students that did not contribute to the lesson but enabled the students to communicate, another goal of the program. These behaviors included talking out of turn or off the topic. The final category, isolation, consisted of behaviors, such as sleeping, playing on cell phones, or arriving to eat a cupcake and then leaving, which did not reflect any value on the book club since they could be done elsewhere. Coding was done by the two library staff. The session environment was so fluid and rapid with students talking and exhibiting simultaneously, however, that it was impossible to get precise counts of behaviors. All that could be concluded from the results were that participation behaviors far outnumbered those in the categories for socialization and isolation. These results indicate to the authors that the activities were at least viable and likely successful by any practical criterion. The academic club also distributed surveys to both students and guardians which all gave positive responses to the program. The academic librarian found a great deal of commonality with the public library clubs to suggest that the book club format is viable for both types of libraries.

\section{Conclusion}

In both public and academic libraries the book clubs satisfied the goals of NCBC to provide an environment for learning and socializing for adults with ID. The clubs also satisfied the goals of both library types to provide inclusive service to a population they have largely neglected. Contrary to assumptions, libraries can provide a valuable service without massive investment in resources and training by extending their skills in collection, outreach, and instruction.

The International Journal of Information, Diversity, \& Inclusion, 3(4), 2019

ISSN 2574-3430, jps. library.utoronto.ca/index.php/ijidi/index

DOI: $10.33137 /$ ijidi.v3i4.33009 


\section{Acknowledgement}

The authors wish to thank the Academy for Community Inclusion, Florida Atlantic University, MacArthur Campus for its support of their work.

\section{References}

American Association of Intellectual and Developmental Disabilities. (2019). Definition of intellectual disability. Retrieved from https: //aaidd.org/intellectualdisability/definition

American Library Association. (2018). Services to persons with disabilities: An interpretation of the Library Bill of Rights. Retrieved from http://www.ala.org/advocacy/intfreedom/librarybill/interpretations/servicespeopledi $\underline{\text { sabilities }}$

Barratt-Pugh, C., \& Rohl, M. (2015). "Better Beginnings has made me make reading part of our everyday routine": Mothers' perceptions of a family literacy program over four years. Australasian Journal of Early Childhood, 40(4), 4-12. https://doi.org/10.1177\%2F183693911504000402

Center for Disease Control and Prevention. (2018). Developmental disabilities. Retrieved from https://www.cdc.gov/ncbddd/developmentaldisabilities/facts.html

Clute, M. A. (2013). Disabilities: Physical disabilities. In Encyclopedia of Social Work: National Association of Social Workers Press. Retrieved from http://oxfordre.com/socialwork/view/10.1093/acrefore/9780199975839.001.0001/acr efore-9780199975839-e-543

Fish, T., \& Rabidoux, P. (2009). Next chapter book club: A model community literacy program for people with intellectual disabilities. Bethesda, MD: Woodbine House.

Learning Disabilities Association of America. (2019). Types of learning disabilities. Retrieved from https: //ldaamerica.org/types-of-learning-disabilities/

Marcotte, A. (2019, June 3). Everyone on the same page: Adults with disabilities find engagement, community in book clubs. American Libraries.

https: / / americanlibrariesmagazine.org/2019/06/03/everyone-same-page-adult-bookclubs/

Mulliken, A., \& Atkins, A. (2009). Academic library services for users with developmental disabilities. The Reference Librarian, 50(3), 276-287.

https://doi.org/10.1080/02763870902873461

National Institute for Neurological Disorders and Stroke. (2019). Learning disabilities information page. Retrieved from https://www.ninds.nih.gov/Disorders/AllDisorders/Learning-Disabilities-Information-Page

The International Journal of Information, Diversity, \& Inclusion, 3(4), 2019

ISSN 2574-3430, jps.library.utoronto.ca/index.php/ijidi/index

DOI: $10.33137 /$ ijidi.v3i4.33009 
Port Washington Public Library. (n.d.). Books for dessert. Retrieved from https://pwpl.org/books-for-dessert/

Port Washington Public Library. (2017). Books for Dessert program manual: Guide for implementing a book club for adults with intellectual and developmental disabilities. Retrieved from http: //www.pwpl.org/wpcontent/uploads/BFD_ProgramManual_09.1_singlePgs.pdf

Wells, S. (1995). Outreach, special needs centers, and mainstreaming services: Options for public library service. In L. L. Walling \& M. Irwin (Eds.), Information services for people with developmental disabilities: The library manager's handbook. Westport, CT: Greenwood Press.

Matthew Conner (mconner@ucdavis.edu) is the author of The New University Library: 4 Case Studies (ALA, 2014) and is the former president of the Librarians Association of the University of California (LAUC). He is currently an instruction and reference librarian at the University of California, Davis.

Leah Plocharczyk (Iplochar@fau.edu) is the interim director of the John D. MacArthur Campus Library at Florida Atlantic University's Jupiter campus, where she oversees all aspects of the library's operation. She is active in mentoring students, as well as in leadership and library outreach. She has published articles on library collaboration with marine mammal stranding networks and conflict management within libraries. She recently finished co-authoring a book about the importance of library book clubs as educational tools for adults with ID.

The International Journal of Information, Diversity, \& Inclusion, 3(4), 2019

ISSN 2574-3430, jps.library.utoronto.ca/index.php/ijidi/index

DOI: $10.33137 /$ ijidi.v3i4.33009 